\title{
FORMATION AND CALCULATION ANALYSES OF THE CYLINDRICAL LATTICED-BUILT-UP-MEMBER-SYSTEM RETICULATED MEGA-STRUCTURE
}

\author{
Yongjun $\mathrm{He}^{1, *}$ and Xuhong Zhou ${ }^{1,2}$ \\ ${ }^{1}$ Professor, College of Civil Engineering, Hunan University, Changsha, 410082, China \\ ${ }^{2}$ Professor, Lanzhou University, Lanzhou, 730000, China \\ *(Corresponding author: E-mail: hyj0087@163.com)
}

Received: 12 April 2009; Revised: 11 November 2009; Accepted: 30 November 2009

\begin{abstract}
An innovative super-long-span spatial structure, cylindrical latticed-built-up-member-system reticulated mega-structure with double-layer grid substructures, is present and studied in this paper. The structural configuration including formation of members of the main structure and layout of the substructures is first analyzed. And the calculation methods are studied, including the equivalent cross-sectional areas of the latticed built-up members, internal forces of the sub-members, and the optimization of the whole structure. Then the optimization analyses of the cross sections of members are carried out aiming for the minimum steel consumption of the structure. In addition, comparison on steel consumption of the reticulated mega-structure with that of the conventional reticulated structure is carried out in detail, and the reasonable span range of the cylindrical latticed-built-up-member-system reticulated mega-structure is last obtained.
\end{abstract}

Keywords: Reticulated mega-structure; formation method; latticed built-up member; substructure; calculation method; optimization analysis

\section{INTRODUCTION}

Today, reticulated shells are widely adopted and their spans tend to become larger and larger. As the simplest type of reticulated shells, the reticulated cylindrical shells, especially the double-layer ones, are employed more extensively than other types of shells. With the development of human society, people have put forward higher requirement for the span of spatial structure (Dong and Yao [1], Makowski [2]). However, for the double-layer reticulated cylindrical shell structure, some problems will occur inevitably with further increase of the span, such as the instability of the whole structure because of the too small structural thickness-to-span ratio, buckling of struts for their oversize lengths and large internal forces, as well as the increasing steel consumption and corresponding economic problems. Multi-layer forms have been applied successfully to shorten members and thus to reduce the probability of strut buckling for the flat grid structure. Besides, the maximum member internal force as well as steel consumption of the structure can be lowered, and the structural stiffness can also be improved. But the effectiveness of multi-layer forms in the reticulated cylindrical shell structure is not so outstanding. Some comparison analyses between the double-layer and triple-layer super-long-span reticulated cylindrical shell structures (Wang and Li [3]) indicated that, it might be impossible to break the restriction of large internal forces and thus to increase structural span by adopting multi-layer forms for reticulated shells. Moreover, the method densifies grids, producing large amount of members. So the double-layer form is more reasonable. But for the super-long-span reticulated shell, double-layer form means long bars with large internal forces in the structure.

How can we break the restrictions of large internal forces and structural overall buckling to construct super-long-span structure? The concept of reticulated mega-structure (He et al. [4]) gives us a satisfactory answer. The whole structure is made up of two levels. The first level is the large grid structure called main structure, which bears all loads and transfers them to the supporting structure. The second level is the substructures embedded in the large grids of the main structure, which only bear the loads within the corresponding large grids and transfer them to the main 
structure. Some researches on the formation method, static properties, seismic performances, and the stabilities of the cylindrical intersecting-latticed-three-dimensional-beam-system (ILTDBS) reticulated mega-structure have been carried out comprehensively and systematically (He et al. [5-7]). Another kind of reticulated mega-structure, cylindrical latticed-built-up-member-system reticulated mega-structure is presented and studied in this paper, including the layout method of substructures, calculation method of the latticed built-up member, and the optimization analyses of the whole structure. Comparison analysis on steel consumption between the latticed built-up member system reticulated mage-structure and the conventional reticulated shell is then carried out, and the rational span for cylindrical reticulated mega-structure is finally recommended.

\section{STRUCTURAL CONFIGURATION AND LAYOUT}

\subsection{The Main Structure and Its Members}

The cylindrical latticed-built-up-member-system reticulated mega-structure braced with conventional grid substructures is an innovative super-long-span spatial structure. As shown in Figure 1, the main structure is a super double-layer cylindrical reticulated structure consisting of latticed built-up members, the large grid size ranges from 10 to $30 \mathrm{~m}$, and the substructures are placed within the upper large grids of the main structure (Not all the substructures are displayed for clarity of the figure). To avoid the serious buckling of the compression members for their oversize lengths, the latticed built-up members are adopted in this paper. As shown in Figure 2, triangle and quadrangle are two basic cross-sectional shapes of the latticed built-up members, and their three or four parallel chords are generally identical and continuous. The transverse and diagonal web sub-members are connected with the chords by directly welded tubular joints(Chiew and Soh [8], Dexter and Lee [9,10]). Web system can take single-diagonal or double-diagonal types. For convenient connection of the latticed built-up members with each other, two cone-shaped ends of each built-up member are adopted as shown in Figure 2, and the built-up members are connected by large welded hollow spherical joints, which are called main nodes of the main structure in this paper and can be treated as pin connection in analysis. Therefore the whole of a latticed built-up member acts as a two-force member within the structure. Since the latticed built-up members are connected with each other by pin connections, the structure must become a geometrically unstable system (Adrin and Virgil [11]) if each sub-member in the built-up members is considered as an element in calculation of the whole structure, and thus the unique solution cannot be obtained. So each latticed built-up member should be equivalently regarded as a single and continuous member in analysis.

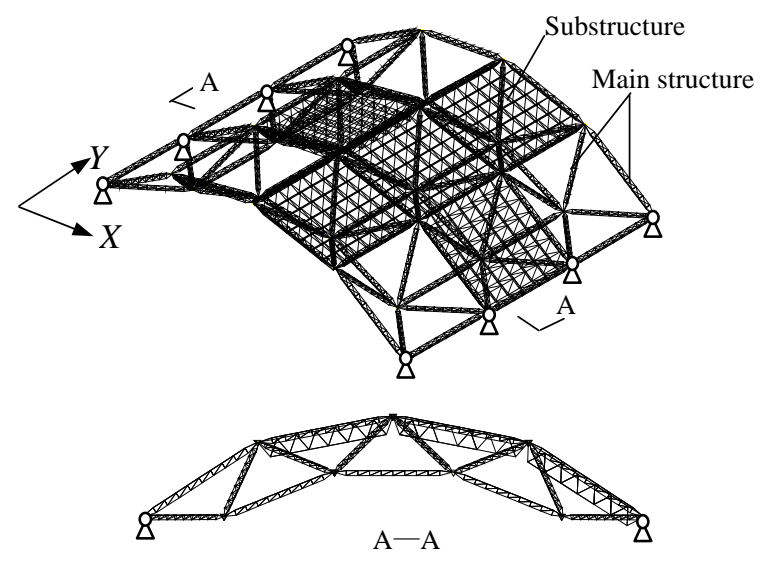

Figure 1. Cylindrical Latticed-Built-Up-Member-System Reticulated Mega-Structure with Double-Layer Grid Substructures
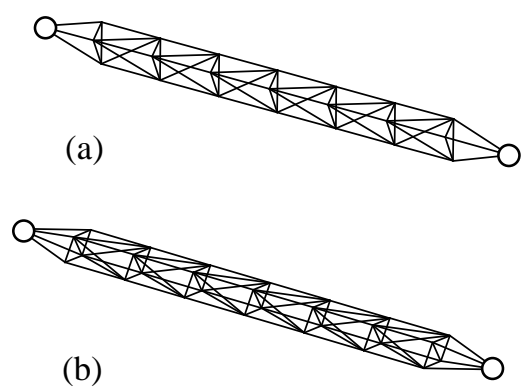

Figure 2. Latticed Built-Up Members: (a) with Equilateral Triangular Cross Section; (b) with Quadrangular Cross Section 


\subsection{Layout Styles of the Substructures}

Because the upper chord latticed built-up members of the main structure are axially loaded members connected with each other by pin connections, the substructures are generally double-layer plane-plate grids, every one of which is supported by four large nodes of the main structure. According to the relationship between two adjacent substructures, there are two layout styles of substructure as shown in Figure 3. The first one is the independent layout as shown in Figure 3(a), in which each substructure is supported independently on the main structure and not

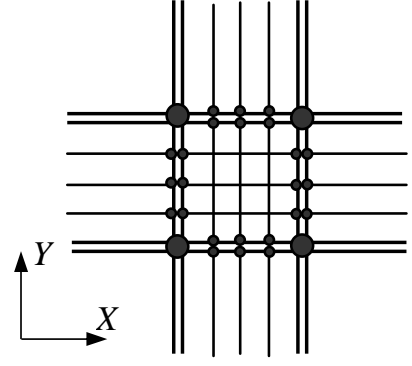

(a) Independent Layout

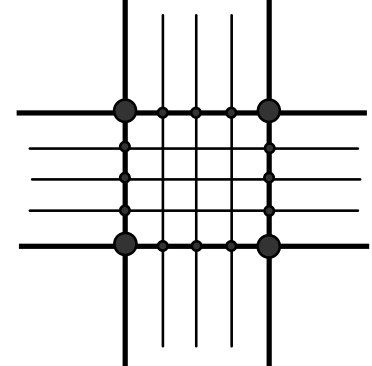

(b) Hinge-Connection Layout

Figure 3. Layout Styles of Substructures

connected with others. And the second one is the hinge-connection layout as shown in Figure 3(b), in which the adjacent substructures are connected together by the common upper chord members and nodes located at their edges, but their lower chord and web members are independent, therefore the common edge of every two substructures is similar to a hinge axis between them. (In Figure 3, the large black dots denote the upper chord main nodes of the main structure, while the small ones present the upper chord nodes along the edges of the substructures.)

\section{CALCULATION METHOD}

\subsection{Calculation of the Latticed Built-up Member}

Based on the accurate calculation of the latticed built-up members subjected to axial load by finite element method (Zienkiewicz et al. [12]), it has been found out that, the axial load of the single-diagonal-type latticed built-up member is basically resisted by the parallel chords, and the internal forces of both the diagonal and transverse rods are almost zero. But for the double-diagonal-type members, besides the parallel chords, the diagonal rods and transverse rods also participate in bearing load.

\subsubsection{Effective cross-sectional area and internal forces of the latticed built-up members}

Here the latticed built-up member with equilateral triangular cross section is first taken as example to study, and some hypotheses, which have been validated by accurate results, are made as follows for convenience of investigation.

(1) The cross-sectional plane of the latticed built-up member still keeps planar after deformation, and 
(2) The equilateral triangular cross section still keeps as equilateral triangular after deformation. So the effective cross-sectional area $A$ of the single-diagonal-type latticed built-up member equals to summation of its three parallel chords, that is,

$A=A_{z 1}+A_{z 2}+A_{z 3}=3 A_{z}$

where $A_{z 1}, A_{z 2}$, and $A_{z 3}$ are the cross-sectional areas of the three parallel chords, and they are generally assumed to be identical as $A_{z}$. Therefore the internal force of each chord is

$F_{z i}=\frac{A_{z i}}{A_{z 1}+A_{z 2}+A_{z 3}} P=\frac{P}{3} \quad(i=1,2,3)$

For the axially loaded double-diagonal-type latticed built-up member, the axial force $P$ at its any cross section is resisted by the parallel chords and diagonal rods as shown in Figure 4. According to the equilibrium condition along the axial direction, the following equation can be obtained.

$6 F_{c} \sin \theta+3 F_{z}=P$

And according to Hooke’s law we have

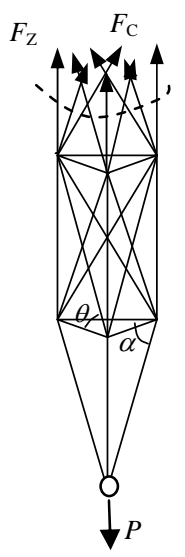

Figure 4. Force Schematic Diagram of the Latticed Built-Up Member

$$
\begin{aligned}
& F_{z}=E \varepsilon_{z} A_{z} \\
& F_{c}=E \varepsilon_{c} A_{c}
\end{aligned}
$$

in which, $\theta$ is the angle between diagonal and transverse rods as shown in Figure 4; $A_{z}, \varepsilon_{z}$, and $F_{z}$ are the cross-sectional area, axial strain, and internal force of a chord, respectively; similarly, $A_{c}, \varepsilon_{c}$, as well as $F_{c}$ are those of a diagonal rod, respectively; and $E$ is the Young's modulus.

Based on hypothesis (1), the following relationship can be obtained.

$\varepsilon_{c}=\frac{\Delta l_{c}}{l_{c}}=\frac{\Delta l \sin \theta}{l / \sin \theta}=\varepsilon_{z} \sin ^{2} \theta$

where $l$ and $\Delta l$ are the length and elongation of a chord in a mid segment, respectively; $l_{c}$ and $\Delta l_{c}$ are those of a diagonal rod, respectively.

According to Eqs. 3, 4 and 5, we have

$$
F_{z}=\frac{P A_{z}}{6 A_{c} \sin ^{3} \theta+3 A_{z}}
$$




$$
F_{c}=\frac{P A_{c} \sin ^{2} \theta}{6 A_{c} \sin ^{3} \theta+3 A_{z}}
$$

Here the effective cross-sectional area $A$ of mid segment of the latticed built-up member is introduced, then

$$
A=\frac{P}{E \varepsilon_{z}}
$$

Based on Eqs. 4a, 6a and 7, one has

$$
A=3\left(A_{z}+2 A_{c} \sin ^{3} \theta\right)
$$

And according to the equilibrium of nodal forces, the internal force of transverse rod $F_{h}$ can be obtained as

$F_{h}=-2 F_{c} \cos \theta$

\subsubsection{Determination of the equivalent cross-sectional area}

As to the axially loaded double-diagonal-type latticed built-up member, the parallel chords, transverse rods, and the diagonal rods all participate in bearing load, so all of these rods should be considered in calculation of its axial elongation. From the force-deformation pattern of the transverse and diagonal rods in a side face of one segment under unit force as shown in Figure 5 and according to the force method, the axial elongation $\delta_{11}$ can be obtained as

$\delta_{11}=\sum \frac{\bar{N}_{i}^{2} l_{i}}{E A_{i}}=\frac{2 \bar{F}_{c}^{2} l_{c}}{E A_{c}}+\frac{\bar{F}_{h}^{2} l_{h}}{E A_{h}}$

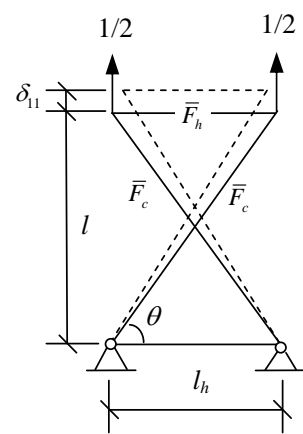

Figure 5. The Force-Deformation Pattern of the Diagonal and Transverse Rods in One Side Face

in which $\bar{F}_{h}$ and $\bar{F}_{c}$ are the internal forces of the transverse and diagonal rods under the action of unit force, respectively.

From Figure 5 we have $\bar{F}_{h}=1 /(2 \tan \theta), \bar{F}_{c}=1 /(2 \sin \theta), l_{h}=l /(\tan \theta)$, as well as $l_{c}=l /(\sin \theta)$. Substituting them into Eq. (10) yields the combined stiffness $k_{11}$ of the transverse and diagonal rods in one side face as follows,

$k_{11}=\frac{1}{\delta_{11}}=\frac{E}{l}\left(\frac{4 \sin ^{3} \theta A_{h} A_{c}}{A_{c} \cos ^{3} \theta+2 A_{h}}\right)$ 
According to the assumption of planar cross sections, as well as the assembling theory of parallel stiffness, the axial elongation $\Delta_{l}$ of one segment under axial force $P$ is

$$
\Delta_{l}=\frac{P}{3\left(k_{11}+E A_{z} / l\right)}=\frac{P l}{E\left(3\left(\left(4 \sin ^{3} \theta A_{h} A_{c}\right) /\left(A_{c} \cos ^{3} \theta+2 A_{h}\right)+A_{z}\right)\right)}
$$

Therefore the equivalent cross-sectional area of mid segment $A_{e}$ is given by

$$
A_{e}=3\left(4 \sin ^{3} \theta A_{h} A_{c}\right) /\left(A_{c} \cos ^{3} \theta+2 A_{h}\right)+3 A_{z}
$$

Similarly, the equivalent cross-sectional area $A_{e}^{0}$ of the whole built-up member accounting for the effect of the two cone-shaped ends can be obtained as

$$
A_{e}^{0}=\frac{9 n A_{e} A_{d} A_{h} \sin ^{3} \alpha}{9(n-2) A_{d} A_{h} \sin ^{3} \alpha+6 A_{e} A_{h}+4 \sqrt{3} A_{e} A_{d} \cos ^{3} \alpha}
$$

where, $n$ is number of segments including the two end cones of the latticed built-up member; $A_{d}$ is the cross-sectional area of the inclined rods at the end cones of the member; $\alpha$ the inclination angle of the inclined rod to the cross-sectional plane of the built-up member, from Figures 4 and 5 we have $\tan \alpha=\sqrt{3} l / l_{h}$; in addition, $A_{e}$ is determined by Eq. 13, but $A_{e}=3 A_{z}$ for the single-diagonal-type latticed built-up member.

Then the elongation $\Delta L$ of the latticed built-up member with length of $L$ under the action of axial force $P$ is given by

$$
\Delta L=P L /\left(E A_{e}^{0}\right)
$$

Obviously, the equivalent cross-sectional area $A_{e}^{0}$ reflects the stiffness character of the latticed built-up member more exactly. And its precision reflects the calculation precision of the whole structure since it will be adopted in overall analysis of the structure.

\subsubsection{Numerical example}

Given that, a latticed built-up member with spacing between parallel chords of $0.625 \mathrm{~m}$ is subjected to a pair of axial force $F=10 \mathrm{kN}$ on the two ends; the total length of the member is $10 \mathrm{~m}$ and it is divided into eight equal segments; in addition, the cross section of all sub-members is $\phi 76 \times 4$. Eqs. 2, 6 and 9 are adopted to calculate the internal forces of various sub-members, while Eqs. 13, 14 and 15 are used to calculate the total elongation of the latticed built-up member. The accurate results are also obtained by finite element method. And the result comparison between the accurate and simplified methods is shown in Table 1, in which both the single-diagonal and double-diagonal types of web system are considered, respectively.

From the table it can be seen that, the axial deformation of the latticed built-up member and the internal forces of various sub-members obtained by the formulas in this paper very consist with the accurate results. Results of the single-diagonal-type member by the simplified method almost have no error in comparison with the accurate ones, and the percentage errors for the double-diagonal-type one also maintain within 3\%. 
Table 1. Result Comparison of Latticed Built-up Members between the Accurate and Simplified Methods

\begin{tabular}{|c|c|c|c|c|c|}
\hline $\begin{array}{c}\text { Type of the } \\
\text { latticed built-up } \\
\text { member }\end{array}$ & Calculation method & $\begin{array}{c}\text { Internal force of } \\
\text { chord members } \\
/ \mathrm{kN}\end{array}$ & $\begin{array}{c}\text { Internal force of } \\
\text { web members } \\
/ \mathrm{kN}\end{array}$ & $\begin{array}{c}\text { Internal force of } \\
\text { transverse rods } \\
/ \mathrm{kN}\end{array}$ & $\begin{array}{l}\text { Total elongation } \\
\quad / 10^{-4} \mathrm{~m}\end{array}$ \\
\hline \multirow{3}{*}{$\begin{array}{l}\text { Double-diagonal } \\
\text { type }\end{array}$} & Accurate method $a$ & 1.506 & 1.022 & -0.912 & 1.101 \\
\hline & Simplified method $b$ & 1.371 & 1.097 & -0.981 & 1.080 \\
\hline & $(|b|-|a|) /|a|$ & $-8.2 \%$ & $7.3 \%$ & $7.6 \%$ & $-1.8 \%$ \\
\hline \multirow{3}{*}{$\begin{array}{l}\text { Single-diagonal } \\
\text { type }\end{array}$} & Accurate method $a$ & 3.336 & - & - & 1.816 \\
\hline & Simplified method $b$ & 3.333 & - & - & 1.810 \\
\hline & $(|b|-|a|) /|a|$ & $-0.09 \%$ & - & - & $-0.3 \%$ \\
\hline
\end{tabular}

Similarly, with hypothesis that the cross sections of various parallel chords are identical, the formula of equivalent cross-sectional area of the latticed built-up member with quadrangular cross section and those of the internal forces of various sub-members in it can be obtained. For the single-diagonal-type member, the internal forces of both the diagonal and transverse rods are all equal to zero, and the internal force of the chord members $F_{z}$ as well as the equivalent cross-sectional area $A_{e}^{0}$ are, respectively, as follows.

$F_{z}=P / 4$

$A_{e}^{0}=\frac{4 n A_{z} A_{d} A_{h} \sin ^{3} \alpha}{(n-2) A_{d} A_{h} \sin ^{3} \alpha+2 A_{Z} A_{h}+2 \sqrt{2} A_{Z} A_{d} \cos ^{3} \alpha}$

But for the double-diagonal-type one, the internal forces of various sub-members are given by

$$
\begin{aligned}
& F_{z}=\frac{P A_{z}}{8 A_{c} \sin ^{3} \theta+4 A_{z}} \\
& F_{c}=\frac{P A_{c} \sin ^{2} \theta}{8 A_{c} \sin ^{3} \theta+4 A_{z}} \\
& F_{h}=-2 F_{c} \cos \theta
\end{aligned}
$$

And its equivalent cross-sectional area is

$$
A_{e}^{0}=\frac{2 n A_{e} A_{d} A_{h} \sin ^{3} \alpha}{2(n-2) A_{h} A_{d} \sin ^{3} \alpha+A_{h} A_{e}+\sqrt{2} A_{e} A_{d} \cos ^{3} \alpha}
$$

where, $A_{e}=4\left(4 \sin ^{3} \theta A_{h} A_{c}\right) /\left(A_{c} \cos ^{3} \theta+2 A_{h}\right)+4 A_{z}$, and the meanings of various notations are the same as before. 


\subsubsection{Stability of the latticed built-up compression members}

As to the latticed built-up members with triangular or quadrangular sections, their cross section should be treated as Class $B$ (Based on the code for design of steel structures of China (GB 50017-2003 [13]) in stability calculation of compression member. The modified slenderness ratios of the single-diagonal-type $\left(\lambda_{s}\right)$ and the double-diagonal-type $\left(\lambda_{d}\right)$ members are respectively given by

$$
\begin{aligned}
& \lambda_{s}=\sqrt{\lambda^{2}+28 A_{z} / A_{c}} \\
& \lambda_{d}=\sqrt{\lambda^{2}+56 A_{z} / A_{c}}
\end{aligned}
$$

in which $\lambda=l / i, \quad i$ is the gyration radius of the latticed built-up member.

The greatest advantage of the latticed built-up member is that its gyration radius can be easily controlled by adjusting the spacing of the parallel chords.

\subsection{Analytical Method for Optimization of Members' Cross Sections}

Once every latticed built-up member is treated as a two-force member, the nodal displacements and members' internal forces of the whole structure under the action of loads can be calculated by matrix-displacement method.

\subsubsection{Cross section optimization of the latticed built-up members}

Conventional full-stress method is generally suitable for cross-sectional optimization (also known as "size optimization") (Gil and Andren [14], Apostol and Santos [15], and Vanderplaats [16]) of space member structure consisting of conventional circular steel tube aiming for the minimum steel consumption. But the latticed built-up members are not continuous member and have no determinate cross section as well as slenderness ratio in advance, so the conventional full-stress method can't be directly adopted to do optimization analysis. Therefore, a so-called fictitious full-stress method for cross-sectional optimization of the latticed built-up members is presented, and the train of thoughts is as follows.

(1) A series of fictitious members, which have determinate cross-sectional areas and rational slenderness ratios, are first given. The optimization calculation for a latticed-built-up-member-system reticulated mega-structure with given large grid size can then be carried out by full-stress criterion, in which the minimum steel consumption is aimed and the assumed members are inputted for optimization selection. And thus the internal force of each fictitious member in the structure can be obtained.

(2) According to the assumed slenderness ratio, the stability coefficient and geometrical parameters of each latticed built-up member can be obtained. And then the cross sections of various sub-members can be determined in light of the calculated internal forces as well as stability coefficients of the fictitious members. 
(3) From the determined cross sections of various sub-members and geometrical parameters of the latticed built-up members, various equivalent variables of the members can be obtained. By calculation of the whole structure again, the actual internal forces of various latticed built-up members can be obtained, and then the cross sections of various sub-members can be checked.

In this method, a series of fictitious cross sections of members are assumed in advance and the optimization is carried out by full-stress criterion, so it is called fictitious full-stress method in this paper. Numerical examples indicate that, it is valid and effective for cross-sectional optimization of the latticed built-up members in the reticulated mega-structure. The concrete example is not given in the paper for the limited length.

\subsubsection{Overall optimization analysis of the structure}

As mentioned above, the substructures are installed in the large grids of the double-layer cylindrical reticulated mega-structure, so the whole structure is composed of the conventional members of the substructures and latticed built-up members of the main structure. If the main structure and substructures bearing loads cooperatively is not considered in optimization calculation, the two levels of the structure can be analyzed independently. Conventional full-stress method is suitable for selection of cross sections of the members in the substructures, and the fictitious full-stress method should be used to obtain the optimal distribution of internal forces of the main structure. And then each latticed built-up member can be designed according to its obtained fictitious internal force. If the main structure and substructures bearing loads cooperatively need to be considered, the cross sections of members can be determined by the combined conventional and fictitious full-stress method. Cross sections of members in the substructures can be selected from the given actual steel tube list by conventional full-stress method; and those of the latticed built-up members of the main structure should be selected from the fictitious cross section series by fictitious full-stress method. By calculation, the obtained cross sections of members in the substructures are the final results, but various sub-members in latticed built-up members of the main structure should be determined by further design according to the obtained fictitious internal forces.

\section{STRUCTURAL OPTIMIZATION AND COMPARISON ANALYSES}

Based on the above-proposed method, a program for analysis of the latticed-built-up-member-system reticulated mega-structure is developed in this paper. The members' cross-section optimization of the whole structure accounting for the substructures' participation in bearing loads cooperatively with the main structure can be done, and the main structure as well as various substructures can also be optimized independently.

\subsection{Comparison Analyses on Whether or Not Accounting for the Substructures’ Participation in Bearing Load Cooperatively the Main Structure}

After being connected to the main structure by large welded hollow spherical nodes, the substructures may participate in bearing load cooperatively with the main structure in a certain degree according to displacement compatibility of the main nodes. Given a structure with span of 80m, comparison analysis on whether or not accounting for the substructures' participation in bearing loads cooperatively with the main structure is carried out in this section. The optimal cross sections of the members are obtained by structural optimization, in which the minimum steel consumption is taken as the objective. And the steel consumption as well as the structural deflection by optimization analysis are listed in Table 2 . 
Table 2. Result Comparison on Whether or Not Accounting for the Substructures' Participation in Bearing Load Cooperatively with the Main Structure

\begin{tabular}{cccc}
\hline Load-bearing state & Steel consumption $/ \mathrm{kg} / \mathrm{m}^{2}$ & Deflection /cm \\
\hline $\begin{array}{c}\text { Independent layout of substructures, and the } \\
\text { substructures participate in bearing load } \\
\text { cooperatively with the main structure }\end{array}$ & (Main structure: 8.1; Substructures: 24.1) & 7.42 \\
$\begin{array}{c}\text { Hinge-connection layout of substructures, and } \\
\text { the substructures participate in bearing load } \\
\text { cooperatively with the main structure }\end{array}$ & (Main structure: $7.5 ; \quad$ Substructures: 22.5) & 6.44 \\
$\begin{array}{c}\text { The main structure bearing load by itself } \\
\text { The }\end{array}$ & (Main structure: 10.5; Substructures: 20.6) & 7.05 \\
\hline
\end{tabular}

From the results it can be seen that, in the case of the main structure bearing load by itself, the cross sections of the upper chord latticed built-up members of the main structure along the transverse direction (i.e. X-direction, as shown in Figure 1) are comparatively large, and the members of the substructures are all conventional steel tubes with relatively small cross sections. However, in the case of the main structure bearing loads cooperatively with the substructures, the cross sections of the transverse upper chord latticed built-up members of the main structure decrease, while those of the members of the substructures at the corresponding positions increase rapidly, especially in the case of hinge-connection layout of substructures. But in this case, the longitudinal (Y-directional) edge chord members of the substructures basically keep the smaller level and have no change, so do the upper chord latticed built-up members of the main structure in the corresponding positions. Additionally, the substructures' participation in bearing loads cooperatively with the main structure leads to increase of the steel consumption of the substructures but decrease of that of the main structure.

Further studies show that, in the case of independent layout of the substructures and their participation in bearing loads being considered, only the cross sections of transverse edge chord members of the substructures change somewhat and those of the interior members almost have no change. This indicates that the substructures' participation in bearing loads is just simple cooperation of the edge chord members of the substructures with the corresponding upper chord latticed built-up members of the main structure. So in this case, there is no need to consider the substructures' participation in bearing loads cooperatively with the main structure. Because it will not only cause the complexity of the connection details, but also lead to the increase of both the total steel consumption and structural deflection as shown in Table 2. However, in the case of hinge-connection layout of substructures, the cross sections of many transverse upper chord members of the substructures increase 2 3 grades for the substructures' participation in bearing load. This indicates that a majority of transverse upper chord members of the substructures participate in bearing load cooperatively with the main structure. And the total steel consumption as well as the structural deflection decrease in a certain degree as shown in Table 2, so the cooperative load-bearing effect is remarkable. Therefore in this case, some measures should be taken to ensure the integrity of the main structure with substructures and thus to consider the cooperative load-bearing effect. Actually, the upper surfaces of all the substructures form a folded plate shell, and the transverse upper chord members of the substructures within a transverse section of the whole structure form a polygonal arch in the case of hinge-connection layout of substructures. 
According to the member distribution of the substructures, which reflects the distribution of internal forces, it can be seen that the internal force flow spreads gradually from the mid area to the two transverse edges of each substructure in the process of being transferred downwards as shown in Figure 6, and it is finally transferred to the supports on the two longitudinal sides of the main

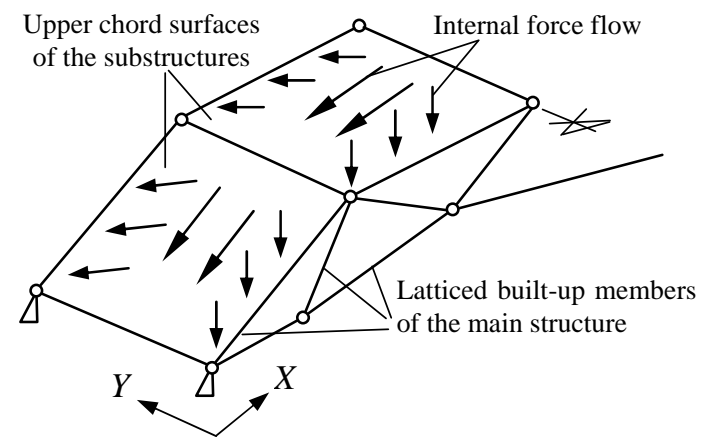

Figure 6. Schematic Diagram of the Force Flow within the Upper Chord Surfaces of the Substructures

structure. The transfer of the internal force flow within the substructures is realized by the web members of the substructures.

\subsection{Comparison Analyses on Whether or Not the Upper Chord Latticed Built-up Members of the Main Structure Are Cancelled}

The substructures are a part of the whole structure. In the case of the substructures participating in bearing loads cooperatively with the main structure, an important character is that the edge upper chord members of the substructures bear load cooperatively with the corresponding parallel upper chord latticed built-up members of the main structure. The substructures' participation in bearing load greatly decreases the cross-sectional sizes of the upper chord latticed built-up members of the main structure. Here a hypothesis is made that the upper chord latticed built-up members of the main structure are canceled and the corresponding load are resisted by the edge upper chord members of the substructures. The previous structure with span of $80 \mathrm{~m}$ is still taken as an example to do comparison analyses on whether or not the upper chord latticed built-up members of the main structure are cancelled. The two layout types of substructures are considered in the case of the substructures participating in bearing load cooperatively with the main structure. From the results it can be seen that, the cross-sectional areas of the edge upper chord members of substructures increase when the upper chord latticed built-up members of the main structure are canceled, but the increase degree is not very remarkable.

Table 3. Result Comparison on Whether or Not the Main Structure’ Upper Chord Built-up Members Are Cancelled

\begin{tabular}{cccccc}
\hline Arrangement method of substructure & \multicolumn{2}{c}{ Independent } & & \multicolumn{2}{c}{ Hinge-connection } \\
\cline { 2 - 3 } \cline { 5 - 6 } $\begin{array}{c}\text { The upper chord built-up members of } \\
\text { the main structure are cancelled or not }\end{array}$ & Cancelled & Not cancelled & & Cancelled & Not cancelled \\
\hline Steel consumption $/ \mathrm{kg} / \mathrm{m}^{2}$ & 30.56 & 32.52 & & 28.92 & 30.05 \\
Deflection $/ \mathrm{cm}$ & 8.16 & 7.42 & & 7.61 & 6.44 \\
\hline
\end{tabular}


And as shown in Table 3, the steel consumption decreases while the deflection increases a little. Therefore, canceling upper chord latticed built-up members of the main structure and making its web and lower chord latticed built-up members bear load cooperatively with the substructures is a feasible structural formation method. And in the case of independent layout of substructures, the cross sections of interior members of the substructures when the upper chord latticed built-up members of the main structure are cancelled and the cooperative load-bearing is considered are identical with those when these members are not cancelled and the cooperative load-bearing is not considered. This indicates that the interior members of substructures don't participate in bearing load cooperatively with the main structure in this case. However, in the case of hinge-connection layout of substructures as shown in Figure 3(b), the cross sections of the transverse (X-directional) upper chord members within the substructures increase obviously when the upper chord latticed built-up members of the main structure are cancelled, and large number of transverse lower chord members also increase a grade, but the web as well as the longitudinal (Y-directional) upper and lower members of the substructures have not any change. Additionally, in this case, the transfer of internal force flow in the upper chord surface of the substructures is still the same as that shown in Figure 6. So the hinge-connection layout style is superior to the independent one for the substructures in the case of the upper chord latticed built-up members of the main structure being cancelled. This kind of structure, in which the substructures are laid out by hinge-connection style and participate in bearing load cooperatively with the web and lower chord latticed built-up members of the main structure, is similar to the composite grid structure (Chen [17]). The substructures of the former correspond to the reinforced concrete upper chord boards of the latter.

\subsection{Steel Consumption Comparison of Different Kinds of Structures}

From the preceding analyses, two structural layout types are suit for the double-layer cylindrical latticed-built-up-member-system reticulated mega-structure. The first one, which is called type-1 reticulated mega-structure, is that the substructures are supported on the upper chord nodes of the main structure independently and do not participate in bearing load cooperatively with the main structure. The second one is that the substructures are hinged together and supported on the upper chord nodes of the main structure. It is named type-2 reticulated mega-structure, in which the upper chord latticed built-up members of the main structure are cancelled, and the substructures have to participate in bearing load cooperatively with the main structure. In this section, optimization analyses for the cylindrical shell structures with different spans are carried out adopting these two types of reticulated mega-structures as well as the conventional reticulated structure, respectively. And comparison analyses on steel consumptions of these three kinds of structures are conducted. In calculation, the uniform vertical load of $1 \mathrm{kN} / \mathrm{m}^{2}$ on the upper surfaces of the structures is considered, and the fixed-hinged supports are set on the upper chord main nodes along the two longitudinal sides of the main structures. The steel consumptions of different kinds of structures obtained by optimization calculation are listed in Table 4.

Table 4. Comparison on Steel Consumption of Different Types of Structures / kg/m²

\begin{tabular}{cccccccc}
\hline Structural type & \multicolumn{7}{c}{ Structural span /m } \\
\cline { 2 - 7 } & 80 & 120 & 160 & 200 & 240 & 280 & 320 \\
\hline Conventional reticulated shell & 20.52 & 23.48 & 29.76 & 39.31 & 44.76 & 49.44 & 56.88 \\
Type 1 reticulated mega-structure & 31.36 & 32.64 & 34.92 & 38.04 & 40.51 & 41.71 & 43.42 \\
Type 2 reticulated mega-structure & 30.00 & 32.90 & 33.81 & 36.68 & 39.06 & 46.21 & 47.40 \\
\hline
\end{tabular}


From the results in the table it can be seen that, the steel consumption increases with increase of the structural span, and the increase rate of the conventional reticulated structure is comparatively fast but that of the reticulated mega-structures is relatively slow. For convenience of comparison, the relationship curves of the steel consumptions of these three types of structures with their structural spans are displayed in Figure 7. Obviously, when the structural span is within 200m, the steel

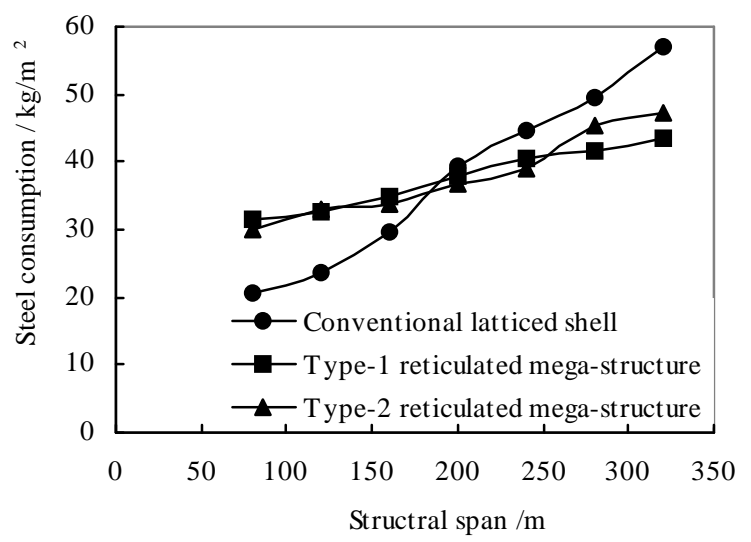

Figure 7. Steel Consumption Comparison of Different

Types of Structures with Change of the Spans

consumption of the conventional reticulated shell is less than those of the mega-structures. But when the span exceeds $200 \mathrm{~m}$, it shows a quick increase and thus becomes higher than those of the latter. So a conclusion can be drawn that, it is better to adopt conventional reticulated structure when the span is within $200 \mathrm{~m}$, on the contrary, it's economical to select the reticulated mega-structure when the structural span exceeds $200 \mathrm{~m}$. In addition, the curve of the type-1 reticulated mega-structure is comparatively flat, and its steel consumption is less than that of the type- 2 reticulated mega-structure when the span exceeds $280 \mathrm{~m}$. This indicates that the independent layout of substructures is more suitable for further extension of the structural span than the hinge-connection style. In the section, just comparison on steel consumption between these types of structures is presented. Actually, when the structural span exceeds $200 \mathrm{~m}$, the peak value of internal forces of the conventional reticulated shell becomes larger and larger and difficult to be handled with further increase of the span. But this problem can be easily solved for the reticulated mega-structure.

\section{CONCLUSIONS}

For the cylindrical latticed-built-up-member-system reticulated mega-structure with double-layer grid substructures, the structural configuration including the formation of members of the main structure and layout of the substructures is first analyzed. Then the calculation methods are studied, including the equivalent cross-sectional areas of the latticed built-up members as well as the internal forces of various sub-members in them, and the optimization of the whole structure. In addition, the structural optimization and comparison analyses with the conventional reticulated shell structure are carried out in detail. Synthesizing the calculations and analyses presented above, some conclusions are drawn as follows. 
(1) The calculation formulas of internal forces of various sub-members of the latticed built-up members and those of equivalent cross-sectional areas of them presented in this paper are very accurate. So the results of overall analysis on the structure based on these equivalent formulas are also comparatively accurate and can satisfy the requirement of practical engineering design.

(2) Fictitious full-stress method presented in this paper is suitable and high efficient for cross-sectional optimization of the latticed built-up members in the reticulated mega-structure, and it can be adopted to do optimization analysis of the whole structure combined with the conventional full-stress method.

(3) By comparison analyses on whether or not the substructures' participation in bearing load cooperatively with the main structure is considered, and whether or not the upper chord latticed built-up members of the main structure are cancelled, two optimal structural layout styles are obtained synthesizing details. The first one is that, the substructures are laid out independently and their participation in bearing loads cooperatively with the main structure is not considered. And the second one is that, the substructures are connected with each other along their edges by hinge connections and participate in bearing load cooperatively with the main structure, besides, the upper chord latticed built-up members of the main structure are cancelled.

(4) By comparison analyses with conventional reticulated shell on steel consumption, it is indicated that the reticulated mega-structure is more economical and suitable for super-long-span cylindrical shell structure, and it is recommended to adopt the reticulated mega-structure when the structural span exceeds $200 \mathrm{~m}$, especially the type- 1 reticulated mega-structure when the structural span exceeds $280 \mathrm{~m}$.

\section{ACKNOWLEDGEMENT}

This work was financially supported by the National Natural Science Foundation of China (Grant No. 50508013), Program for New Century Excellent Talents in University (Grant No. NCET-07-0266), Natural Science Foundation of Hunan Province for Distinguished Young Scholars (Grant No. 08JJ1006), and National Key Technology R\&D Program (Grant No. 2006BAJ18B06-01), which are gratefully acknowledged.

\section{REFERENCES}

[1] Dong, S.L. and Yao, J., “The Future and Prospect of Latticed Shell Structures”, Spatial Structures, 1994, Vol. 1, No. 1, pp. 3-10 [in Chinese].

[2] Makowski, Z.S., "Space Structures of Today and Tomorrow”, Space Structures, Guildford, Elsevier, 1984.

[3] Wang, B.B. and Li, Y.Y., “A Theoretical Study of Super-span Latticed Shells”, Journal of Constructional Steel Research, 1999, Vol. 51, pp. 287-96.

[4] He, Y.J., Zhou, X.H., Liu, Y.J., Dong, S.L. and Li, J., "Super-span Reticulated Mega-structure”, Journal of Architecture and Civil Engineering, 2005, Vol. 22, No. 3, pp. 25-9 [in Chinese].

[5] He, Y.J. and Zhou, X.H., "Static Properties and Stability of Cylindrical ILTDBS Reticulated Mega-structure with Double-layer Grid Substructures”, Journal of Constructional Steel Research, 2007, Vol. 63, No. 12, pp. 1580-1589. 
[6] He, Y.J., Zhou, X.H., Dong, S.L. and Li, J., "Seismic Performance of Cylindrical Latticed-intersected-three-dimension-beam-system Reticulated Mega-structure with Double-layer Grid Substructures”, International Journal of Advanced Steel Construction, 2006, Vol. 2, No. 1, pp. 22-36.

[7] Zhou, X.H., He, Y.J. and Xu, L., "Stability of a Cylindrical ILTDBS Reticulated Mega-structure with Single-layer Grid LICS Substructures”, Journal of Constructional Steel Research, 2009, Vol. 65, No. 1, pp. 159-168.

[8] Chiew, S.P. and Soh, C.K., "Strain Concentrations at Intersection Regions of a Multi-planar Tubular DX-joint”, Journal of Constructional Steel Research, 2000, Vol. 53, No. 2, pp. 225-244.

[9] Dexter, E.M. and Lee, M.M.K., "Static Strength of Axially Loaded Tubular K-joints I: Behavior”, Journal of Structure Engineering, ASCE, 1999, Vol. 125, No. 2, pp. 194-201.

[10] Dexter, E.M. and Lee, M.M.K., "Static Strength of Axially Loaded Tubular K-joints II: Ultimate capacity”, Journal of Structure Engineering, ASCE, 1999, Vol. 125, No. 2, pp. 202-10.

[11] Adrin, G. and Virgil, D., “Geometry of Structure Forms”, London, Applied Science Publishers Ltd., 1978.

[12] Zienkiewicz, O.C., Taylor, R.L., and Zhu, J.Z., “The Finite Element Method: Its Basis and Fundamentals (Sixth Edition)”, Oxford, Elsevier Butterworth-Heinemann, 2005.

[13] Ministry of Construction of the People's Republic of China, "GB 50017-2003, Code for Design of Steel Structures of China”, China Planning Press, 2003.

[14] Gil, L. and Andreu, A., "Shape and Cross-section Optimization of a Truss Structure", Computers \& Structures, 2001, Vol. 79, No. 7, pp. 681-689.

[15] Apostol, V. and Santos, J.L.T., "Sensitivity Analysis and Optimization of Truss/Beam Components of Arbitrary Cross-section I-Axial Stresses”, Computers \& Structures, 1996, Vol. 58, No. 4, pp. 727-37.

[16] Vanderplaats, G.N., “Numerical Optimization Techniques for Engineering Design”, New York, McGraw-Hill, 1984.

[17] Chen, H.J., “Analysis and Optimum Design of Composite Grid Structures (5th Edition)”, Stanford, Stanford University, 1994. 